\title{
Identity at work: Exploring strategies for Identity Work
}

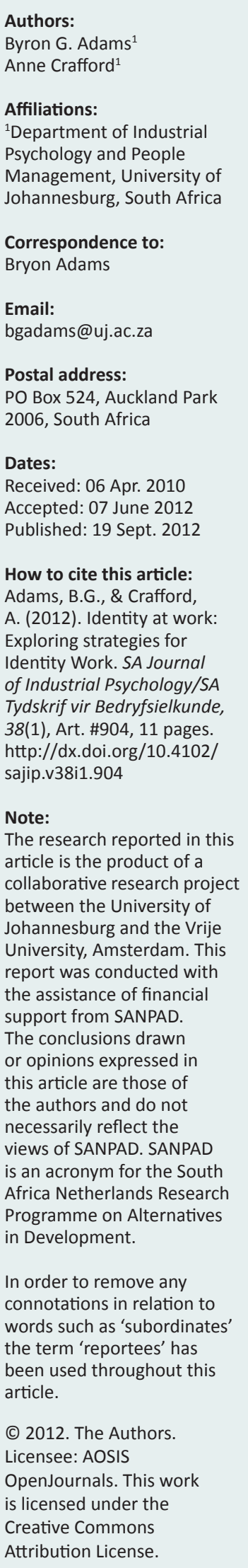

Authors:

Byron G. Adams

Affiliations:

Management, University of

Correspondence to

Bryon Adams

Email:

Auckland Park

Dates:

Accepted: 07 June 2012

How to cite this article:

Adams, B.G., \& Crafford,

Identity Work. SA Journa

of Industrial Psychology/SA

Tydskrif vir Bedryfsielkunde,

sajip.v38i1.904

Note:

article is the product of a

collaborative research project

report was conducted with

the assistance of financial

support from SANPAD.

the conclusions drawn

necessarily reflect the

Africa Netherlands Research

Programme on Alternatives

in Development.

connotations in relation to

the term 'reportees' has

been used throughout this

Licensee: AOSIS

OpenJournals. This work

Creative Commons
Orientation: This study explored strategies for identity work that are central to the negotiation and regulation of employee work identity.

Research purpose: The main aim of this study was to explore employee narratives and identify the strategies available to them in the process of identity work, as they defined themselves at work.

Motivation for the study: As there is a scarcity of research on identity work in South Africa, this study wanted to advance knowledge about identity work and the strategies used for regulating and negotiating an identity at work by exploring these constructs in this context.

Research design, approach and method: A qualitative research process formed the basis for this study. Nineteen employees from a global manufacturing company participated in two semi-structured in-depth interviews. Grounded theory was applied to analyse and interpret the data.

Main findings: Nine strategies for identity work were identified and categorised into four broad themes (personal philosophies; relationships; career management and negotiating balance).

Practical/managerial implications: Employees followed various strategies for defining themselves at work and this may have some implications for employee work engagement and productivity.

Contribution/value-add: This study expands on current theoretical knowledge of identity work, and provides insights into the strategies people use to regulate and negotiate their identities at work.

\section{Introduction}

People are constantly in the process of defining themselves by drawing on and engaging with various environments and contexts, such as, family, work, friends, religious groups and leisure activities. During this process of self-definition people consciously make decisions that allow them to function effectively between and within different and often contradictory contexts, as identity is informed by both personal and social aspects (Ashmore, Deaux \& McLaughlin-Volpe, 2004; Hogg, Terry \& White, 1995; Verkuyten, 2005). For example, an Islamic mother who is an accountant by profession is influenced by several distinct contexts that require her to manage various expectations and demands. These include being the mother of a family, a member of a particular religious group, a member of a profession, and an employee of an organisation. The purpose of this article is to explore the strategies people follow in identity work in order to regulate and negotiate their identities at work. The study views identity as being negotiated in relation to multiple contexts that inform and influence identity.

Three concepts are core to the understanding of how people manage the demands made by both the personal and social aspects of their identities. These three concepts are work identity, identity work and strategies for identity work. The term work identity refers to identity at work, and focuses on who a person is at work and how he or she is defined within the context of work (Alvesson, 2001; Brown, 2004; Buche, 2006; Kirpal, 2004; O'Conner, 2007; Sluss \& Ashforth, 2007; Svenningson \& Alvesson, 2003; Swann, Johnson\& Bosson, 2009; Walsh \& Gordon, 2008). The term identity work refers to the process of negotiating and regulating identity (Ainsworth, 2001; Alvesson \& Willmott, 2002; Beech, 2008; Rounds, 2006; Svenningson \& Alvesson, 2003; Watson, 2008). In this article this process is discussed within the context of work. Finally, the term strategies for identity work refers to the actual decisions and actions taken for regulating identity (Iedema \& Scheeres, 2003; Kornberger \& Brown, 2007; Kreiner, Hollensbe \& Sheep, 2006; Rothbard \& Edwards, 2003). Much of the research on work identity, identity work and strategies for identity 
work has been conducted in America and Europe, and this study is therefore novel in that it provides insight into how these aspects may relate to the African and, in particular, the South African contexts. South Africa contains some unique dynamics, including unique labour legislation, a diverse work force and a history of transformation particularly within the work environment (Eaton \& Louw, 2000; Jackson, 1998; Van de Vijver \& Rothman, 2004), which may provide different challenges as employees negotiate and regulate their identities at work.

\section{Identity, work and work identity}

Personal identity is the outcome of a dynamic, conscious and on-going struggle to establish an answer to the question 'who am I' (Sveningsson \& Alvesson, 2003). Identity is inherently social, as people are and need to be a part of something greater than themselves (Kreiner et al., 2006). In the example cited above the mother is simultaneously a woman of a particular age and ethnicity and also part of a family, religious group, profession and organisation. Whilst some of these characteristics, such as age or gender, are fairly stable other characteristics such as profession and dress are fluid and open to choice (Adams, Van de Vijver \& De Bruin, in press; Giddens, 1990). People tend to place emphasis on the roles that they consider are representative of themselves (Rothbard \& Edwards, 2003). Work is an important social context and thus provides much material for the development of identity. Gini (1998) emphasises the importance of work by referring to the growing impact it exerts by consuming the time and energy of an individual. Work not only allows people to meet their basic needs, it also provides one of the most critical social contexts in which people negotiate identity (Gini, 1998; Philipson, 2001).

Work identity is a multi-dimensional and multi-layered construct that provides a social representation of how individuals interact within their employment environment (Buche, 2006). In this regard Kirpal (2004) stresses the importance of work identity, and argues that work identity is linked to the following contexts:

forms of identification individuals develop with their job, work setting or their employer...[and] it is through identification with the work environment, the company or work related activities and tasks which individuals perform, that makes individual and collective productivity possible. (p. 274)

In addition, the context and type of work identity plays a critical role in the development of a personal identity, and contributes to establishing psychological links between people and their work, thus culminating in the development of employee engagement (Leidner, 1991). Work identity, therefore, seems to be an underlying condition of productivity, as productive individuals need to be engaged in their work and a strengthened work identity facilitates work engagement that is associated with increased productivity (De Braine \& Roodt, 2011).

\section{Identity work at work}

Although people need to define themselves as unique beings they are also confined to the various social contexts in which they function. Within the context of this article, the prominent social context is the work context. Thus, although a person might emphasise the 'I am' aspect of their identity, there is also cognisance that 'I am also a part of' a context. The self must therefore be continuously negotiated relative to and within the context of work. This process of identity creation, regulation, negotiation and modification is known as identity work and requires the individual to actively engage in 'forming, repairing, maintaining and strengthening or revisiting the constructions that [are] productive of a sense of coherence and distinctiveness' (Sveningsson \& Alvesson, 2003, p. 1164). Watson (2008) highlights the tensions and struggles involved in identity work and refers to the 'subjectivities...caught up in contradictions, struggles, tensions, fragmentations and discords' (p. 124). Identity work thus involves a careful balance and resolution of the tensions between the self and the general demands of the work context in which the individual's identity is negotiated (see also Beech, 2008; Swann et al., 2009). Within this article the process of seeking constant balance between an individual's personal identity and the demands made by work is referred to as 'identity work at work'.

The authors argue that organisations should be keen to regulate employee work identity to ensure that they identify more strongly with the values and culture of the organisation. Organisations attempt to facilitate engagement by eliciting commitment towards organisational goals. As employees tend to align themselves with those attributes of their work and organisation which they consider important, they also tend to resist those attributes which they perceive as incongruent with who they are and would like to be. This process of alignment involves the taking of action (Beech, 2008) which is the strategy employees make use of to regulate and negotiate their identities.

\section{Strategies (tactics) in identity work}

There are several perspectives on strategies in identity work. Breakwell (1986) first considered these strategies in terms of threatened identities and identified several coping strategies employed by people to protect their identities. Breakwell's (1986) strategies include:

- intrapsychic strategies, which are strategies of selfprotection on the intrapsychic level (p. 77)

- interpersonal strategies, in terms of changing relationships with others as a means of coping with threat (p. 109)

- intergroup strategies, which operate at a series of group levels and at varying group structures (p. 128).

In contrast, the study of Kreiner et al. (2006) of work identity in the ministerial context, which makes 'significant identity demands' (p. 1039), focuses on the 'how' of identity work, and developed a model for classifying strategies. According to this model strategies are placed into three categories that are aimed at creating a balance or finding equilibrium between the self and work. These categories are differentiation, which places emphasis on defining the unique self; integration, which places emphasis on including 
the self with work; and dual-function strategies, which can be used to either differentiate the self from work or integrate the self with work. Strategies therefore involve the process of reconciling the tension expressed by people seeking meaning in their lives within the context of work through actions and decisions-making (Rounds, 2006). The work environment requires significant personal investment that differs from the relatively superficial investment required by other social identities, which means that strategies at work are often quite purposefully developed.

In order to make sense of this process Beech (2008), Kornberger and Brown (2007) and Watson (2008) propose more contemporary perspectives on strategies for identity work at work. These perspectives highlight the importance of narrative and discursive perspectives for work identity strategies. The authors' approaches to the study of identity development can be described as narrative exercises, where the expression of strategies takes the form of stories people tell about themselves by drawing on the discursive resources they have at their disposal. This is very different to the more static classification of identity work of Kreiner et al. (2006). This discursive, narrative approach to exploring strategies for identity work is reflected in the methodological approach of this study, which used story telling as a means of gathering data about identity work and work identity.

\section{This study}

This study forms part of a larger study on work identity in South Africa funded by SANPAD. In this study the authors explore identity work and moreover the strategies followed to negotiate and regulate identity at work. The authors aim to perform this by examining employee narratives and considering the decisions, actions, activities and behaviours they would undertake in the process of identity work at work. The research question was: What practices, passions and relationships which could be interpreted as strategies do employees make use of in their attempt to define themselves at work?

\section{Research design Research approach}

Qualitative field research was undertaken to explore and gain insight into the strategies people follow in negotiating work identity (Bailey, 2007; Neuman, 2000; Parker, 2005). This approach allowed the researchers the opportunity to understand how people construct their social reality and negotiate identity within their social and particularly work contexts. The aim was to obtain detailed comprehensive explanations, described by Denzin (1989) as 'thick description', but which are also known as 'detailed stories' (Esterberg, 2002, p. 50) or 'rich data' (Charmaz, 2010, p. 14), of how people view their world by considering their experiences and interpretations of their reality (Guba \& Lincoln, 1994; Rubin \& Rubin, 1995). This study formed part of a larger research project on work identity and the research team, thus, consisted of seven students (who also served as fieldworkers) and five supervisors.

\section{Research Method}

\section{Sampling}

A purposive sampling process was followed (Mason, 2002). Twenty-eight individuals representing different business units, and at different levels in the organisation, were selected by the organisation based on their willingness to participate. It was important that the sample was diverse in terms of gender, race, age, education and socioeconomic status. From these 28 individuals, a subsample of 19 participants were analysed in this study. The interviews of these participants were fully transcribed, this was important as the transcriptions of their narratives provided the researchers with the contexts needed to truly understand and represent their perspectives as participants (Esterberg, 2002). The subsample remained representative of the different business units and levels in the organisation, and consisted of 3 Asian participants, 4 Black participants, 3 Coloured (people of mixed ethnic descent) participants and 9 White participants. The sample consisted of 13 males and 6 females. The ages of participants ranged from 27 to 58 .

\section{Research setting}

Data were gathered in one of the plants of an international manufacturing organisation based in Gauteng, South Africa. This provided an opportunity to explore work identity within a demanding work environment. The organisation selected for this study is characterised by the high demands it places on its employees, as production and quality are crucial for its success. Employees are also often 'on-call' (expected to come to work at short notice) during weekends and evenings, which places demands on the employees' time and personal resources, as they are expected and required to work long hours in order to meet production requirements.

Ethical issues concerning confidentiality, disclosure and informed consent were discussed with the participating organisation prior to entry and with participants prior to their interviews. Employees were briefed about interview procedures and provided their consent through standardised consent forms.

\section{Entrée and establishing researcher roles}

As the study formed part of a larger project, the research team obtained entry into the research setting (the organisation) as a unit, through a gatekeeper (Walsh, 1998). The project leader was responsible for liaising with the gatekeeper for the purpose of gaining entry.

The researchers' role was that of research instrument. In this respect, the researchers considered it a privilege to interact with individuals and act as a custodian of their stories (Esterberg, 2002). The researchers are guided by ethical responsibility, which required reflection of personal biases, views, moods and emotions when interacting with participants. 


\section{Data collection}

Two rounds of interviews were conducted by seven fieldworkers in a two week period. Each researcher interviewed four individuals. The first round of interviewing was very exploratory. The interview process was centred on the question 'Tell me your story?' This question was broad enough to allow participants to discuss their decisions, actions, activities, and behaviours freely in their own words (Goulding, 2007). The participants were encouraged to discuss significant passions, practices and relationships (McAdams, 1993) that they engaged in. This question also allowed participants to discuss freely both personal and work related aspects that the researchers considered important for understanding how work identity is negotiated and regulated.

Following the first round of interviews, the fieldworkers met for a peer debriefing session. This session provided a forum for discussing the initial perspectives and preparation for the second round of interviews.

The second round of interviews followed shortly after peer debriefing and the purpose of this second round was to confirm the data from the first interview and further investigate unexplored areas. After the second round of interviews another peer debriefing session was held, where global themes and misconceptions about the data were discussed (McMillan \& Shumacher, 2001).

\section{Recording of data}

All interviews were electronically recorded and fieldworkers were responsible for transcribing these interviews either themselves or by others. These transcriptions were made available to team members involved in the debriefing sessions, the initial analysis and to the students who would include these in their respective studies. It was the responsibility of the team member who had access to the data to safeguard the data in their possession and maintain traceable records. In this study, the authors randomly labelled the interviews of the 19 participants with a combination of Roman or Arabic numerals and Arabic letters.

\section{Data analysis}

In the life stories of participants the researchers wanted to make sense of how they had come to define themselves at work and the strategies they had followed within the context of their working lives. Grounded theory, as the strategy of data analysis, provided a 'systematic procedure for shaping and handling' (Charmaz, 1995, p. 28) the data (Charmaz, 2010; Esterberg, 2002; Goulding, 2007). The researchers could give meaning to the data and make sense of the data by identifying communalities that may be present between the stories of different participants.

In the initial coding process, the open coding of incidents and events were coded. The researchers focused on answering the question of 'whether a practice, passion and relationship could be related to a particular decisions, actions, activities and behaviours that might impact and individual's work identity'. This initial analysis yielded 378 rough codes. These codes were placed onto an Excel spreadsheet. Each code was reviewed and codes that were similar were consolidated to reflect the initial relationships identified by the researchers. This was a process of more focused coding and it scaled the original 378 rough codes down to 59 categories.

The review process was repeated and 15 strategies were identified, through axial coding. These strategies were revised, after this article was submitted for review to the current journal, and further reduced using axial coding to the nine strategies reported in this manuscript. The process of axial coding uses the original data to validate the final thematic categorisation, in this case the nine strategies, identified by the researchers (Charmaz, 2010). In order for an aspect to be classified as a strategy the following criteria needed to be met: firstly, it needed to be an aspect in which individuals actively engage and, secondly, it should have a direct or indirect effect on their work identity.

The nine strategies represented the researchers' interpretation of the regulatory and negotiation process followed by participants in identity work. Strategies were classified according to conceptual and theoretical communalities, evident in the strategies, into four main themes of identity work. This final categorisation could be viewed as an artefact of the researchers' role in interpreting the results (Charmaz, 2010; Esterberg, 2002; Goulding, 2007; Reetley, 2003).

\section{Strategies to ensure quality of data}

Parker (2005) considers reflexivity to be a process 'working with subjectivity in such a way that we are able to break out of the self-referential circle that characterises academic work' (p. 25). The process of reflexivity was part of ensuring the validity of the analysis, interpretation and representation of participants. Reflexivity allowed the researchers to consider their roles as interpreters of the participants' stories (Esterberg, 2002; Sparkes, 2002). In addition to aspects already mentioned in this section, the following strategies also ensured the quality of the data.

Although the primary researcher was responsible for ensuring the quality of the data, there were some aspects in which the larger research team was instrumental. Prior to the commencement of the interview process all interviewers underwent training on qualitative interviewing techniques. During and directly after the data collection, the project team had debriefing sessions where qualitative research experts were present to provide a context for dialogue and reflection on the research process, the data obtained and the researcher's role in this process. Each research member was encouraged to keep personal field notes accounting for their behaviours and actions during and after interviews (Adler \& Adler, 1994). During the data analysis stage for this article the researchers met for reflective sessions to validate the codes, categories, strategies and themes with original narratives. 


\section{Reporting}

The creation of meaning is central to the interpretive paradigm. This research is therefore reported in a manner similar to a confessional tale (Sparkes, 2002). The research refers to selected extracts, and often several extracts, from the interviews to substantiate the strategies identified. Nine strategies were identified, and these strategies have been clustered under relevant themes that accentuate the clear links between certain strategies. Qualitative studies always aim to do justice to the participants when reporting the findings, and the extracts were, thus, kept as close to verbatim as possible. This is in keeping with the reporting strategy. However, at certain points some of the extracts have been adapted slightly in order to enhance the overall sense-making of the extract. In these cases clear indication of adaptations is given by using parenthesis.

\section{Findings}

The authors discuss the nine strategies identified, as categorised under the following four broad themes:

- personal philosophies

- relationships

- career management

- negotiating balance.

Table 1 provides a summary of the themes and strategies. The descriptions of respective themes and strategies are based on our interpretation of the data.

\section{Theme 1: Personal philosophies}

Personal philosophies refer to strategies people follow to make sense of their world and cope with difficulties in their work lives. The authors suggest that this strategy underpins all the subsequent strategies as it involves personal beliefs, morals and values that influence all spheres of life. This theme includes two strategies, living work ethic and living personal ethic.

\section{Strategy 1: Living work ethic}

Living work ethic consists of the attitudes, beliefs and values people hold relative to their work and the organisation that provides them with work. This strategy guides how people engage with their work, which in turn influences their work identity and the value they place on their work. It includes aspects such as commitment to work, job satisfaction, the proactive completion of work tasks, and taking responsibility for work. Within this strategy pride for both work and the organisation are crucial as this reflects commitment. In the extract below the person mentions that she does what needs to be performed when she must, she tries to be ahead in her work as she 'enjoys being on top of things' (Interview VE, page 9; hereafter VE, p. 9). This is part of the values and attitudes she has towards her work:

'But I do work hard and I do work well and what I do I do well, you know, and I enjoy coming to work and doing something and lots of times I'll see an email and I'll take action (around) it and do it and he will send me an email the next day saying 'please do it' and I'll mail him back and say 'I have already done it and here is the information,' you know, things like that. I enjoy being on top of things ... that's generally my attitude now; I do my best, in the production site things happen.' (Participant VE, international manufacturing organisation employee, p. 9)

Within this strategy special attention was given to how meaning is created at work as this reflects gratitude, joy, pride, passion for work, and how participants make sense of the difficulties that they experience. These aspects are significant in the context of this paper because the way in which people make sense of their world or work provides them with purpose and drive to accomplish their work goals, thus constituting a powerful strategy. Creating meaning at work deals with the value people find in 'being' and assists in their progress towards self-actualisation whilst considering aspects such as the security that work provides and the value of their work. In the following extract the person describes how he survives by choosing to be happy. He refers the example of his wife who constantly complains about her work, and her desire to be as happy as he is in his work. He

TABLE 1: Strategies in identity work at work.

\begin{tabular}{|c|c|c|}
\hline Strategy & Label & Definition \\
\hline \multicolumn{3}{|c|}{ Theme 1: Personal philosophies } \\
\hline Strategy 1 & Living work ethic & $\begin{array}{l}\text { Living work ethic that guides decisions and behaviour, whilst creating meaning when faced with difficult } \\
\text { situations at work. }\end{array}$ \\
\hline Strategy 2 & Living personal ethic & Living personal ethic that provides guidance for decisions and behaviour in life, also including work. \\
\hline \multicolumn{3}{|c|}{ Theme 2: Relationships } \\
\hline Strategy 3 & Relationship work & Investing in relationships and actively manage these relationships to achieve goals. \\
\hline Strategy 4 & Managing relationships with family & Participating in family relationships and deriving fulfilment, strength and motivation from these. \\
\hline Strategy 5 & Managing relationships at work & $\begin{array}{l}\text { Engaging in relationships at work to gain emotional support, and networking to achieve their work } \\
\text { goals. }\end{array}$ \\
\hline \multicolumn{3}{|c|}{ Theme 3: Career management } \\
\hline Strategy 6 & Education & $\begin{array}{l}\text { Educating (formal and informal) oneself because it provides the knowledge and skill to work } \\
\text { successfully. }\end{array}$ \\
\hline Strategy 7 & Career mobility & Moving between organisations to achieve work related, career, financial, and personal goals. \\
\hline \multicolumn{3}{|c|}{ Theme 4: Negotiating balance } \\
\hline Strategy 8 & Managing boundaries & $\begin{array}{l}\text { Managing one's boundaries and making decisions that enhance temporal flexibility and relaxation to } \\
\text { achieve work-life balance. }\end{array}$ \\
\hline Strategy 9 & Work-life integration & Integrating work into life and vice versa in order to become more holistic. \\
\hline
\end{tabular}


mentions that the importance lies in 'generating' his own happiness in order to cope with the difficulties faced at work: 'Generate the happiness or you won't make it' (Participant IIIC, international manufacturing organisation employee, $\mathrm{p}$. 15). This reflects a deliberate and conscious effort to choose contentment at work instead of focussing on negative aspects.

\section{Strategy 2: Living personal ethic}

Living personal ethic represents a moral and ethical code by which participants live and includes the attitudes, beliefs and values that influence their behaviour. This is a strategy as it guides how people engage not only with their work but also with the world in general. In terms of work this strategy provides guidance for behaviour and, thus, identity. It includes aspects of integrity, respect, and self-discipline. In the following extract the person discusses his knowledge about what is right and wrong, the standard against which he measures his own and others behaviour:

'Then he gave me an envelope at the end of the meal and I took the envelope and I thought what the hell is this? When I got to the car I opened it and there was R2000 in the envelope. That was Friday afternoon at 14:00. By 9 o'clock the Monday morning I still hadn't make a decision about what I was going to do with the money. It was an absolute tug of war. And I walked into the finance manager's office. I said 'The butcher gave me R2000 for the Christmas fund, please write him a letter and thank him' and I walked out, but at that point in time that money would have been an absolute life saver. I couldn't take it. But conversely that same year Company A gave me 3 increases in one year. My finance manager, $\mathrm{Mr} \mathrm{X}$, said to me, when I put the first letter down, 'this is really irregular...' Oh yes, I have a very, very powerful sense of what I believe is right and wrong, from a moral ethical, it's like a bedrock. When I see other people acting in an immoral or unethical manner I get very chirpy.' (Participant IVD, international manufacturing organisation employee, p. 4)

This extract shows a strong personal ethic guiding behaviour at work. The person states that 'I couldn't take it' even when the money would have made personal circumstances much easier and he appears to have experienced some indecision. In the final instance, however, the moral 'bedrock' makes deviation from this personal ethic too difficult.

Within this strategy the consideration of Religious and Spiritual Beliefs seems to play an important role in people's lives. This is regarded as a strategy because people faced with difficulties often seem to draw from this arena in order to find renewal and strength to continue. Although this was not mentioned by all the employees, for some employees their beliefs provide a source of comfort and guidance, as illustrated by the extract below:

'I am able to say Lord this is not about me and be there for others; fulfil my duties. There is always hard work to do, outside of your challenges. Leave it to him because He gives you the strength.' (Participant 5A, international manufacturing organisation employee, p. 8)

\section{Theme 2: Relationships}

Relationships proved to be a strategy followed consistently by people to reinforce their identities. Given the importance of relationships in identity this finding was not surprising. People refer to their relationships to define themselves and establish what is important in their lives. However, the study found different foci in the use of relationships.

\section{Strategy 3: Relationship work}

Relationship work refers to the effort people invest in managing their relationships. This is an important strategy because it highlights the importance of the conscious thought participants engage in as part of their relationship with others. Individuals consciously decide whether or not to engage or not engage in relationships and also decide how their effort will best be invested. Through the use of phrases such as 'like you help you' and 'respect', people found that managing their relationships enhanced the way in which they identified with their work. This enhancement included seeing the value of diversity and working with people with differing views. It also involves an understanding that they require others to accomplish their work. In another interview the importance of respect was raised. In this instance the person was working in diverse environments with different people and found that by being respectful he could reach them and earn their trust: 'I think the key is respect. I haven't always been respectful' (Participant IVD, international manufacturing organisation employee, p. 14).

Furthermore, relationship work involves investing in relationships, and quite often adjusting relational behaviour (in this case the management of conflict) to fit the context, as indicated in the following extract: 'The way I deal with conflict at work is completely different to the way I (deal) with it at home' (Participant 12A/B, international manufacturing organisation employee, p. 6).

\section{Strategy 4: Managing relationships with family}

Relationships with family are seen as a crucial part of personal identity. Family relationships are seen as a way of maintaining the self. These relationships are valuable as they provide support beyond work and fulfil those relational needs that cannot be met by work. Relationships with family are considered a strong regulator of work identity, as these relationships provide a break from work. Many of the employees referred to their relationships with their wives, husbands, children and parents as sources of fulfilment and strength. Consider the following three extracts:

'Most fulfilling (relationships are) with my husband and my children.' (Participant 12A/B, international manufacturing organisation employee, p. 3)

'At the moment my wife and the kids [are there], my wife is my backbone.' (Participant 2A/B, international manufacturing organisation employee, p. 6)

'The most fulfilling relationship that I have is with my wife because I spend most of my time with her, we understand each other, [and] yes we have our ups and downs.' (Participant 10A/B, international manufacturing organisation employee, p. 3)

Some of the individuals focused on the important role their parents play in their lives. Two individuals highlighted the 
values their mothers had communicated to them as crucial in building their own character and value system as people. These aspects contribute towards who they are at work and how they relate to others. Consider the follow extract:

'I have a very special relationship (with my mom) and I based my life on her aspirations to make sure that you never let people down no matter what, and she made me very strong that way.' (Participant 1A/B, international manufacturing organisation employee, p. 2)

This extract also reinforces the importance of personal philosophy (such as 'never let people down') in work identity, and provides a link between the strategies of personal philosophies and relationships at work. It also highlights the importance of relationships in the formation of personal philosophies and, thus, reinforces the relational nature of identity.

\section{Strategy 5: Managing relationships at work}

In the theme, 'Relationships at work', participants emphasised the importance of good relationships in the working environment for various reasons, including the achievement of work goals, the provision of feedback and for support and guidance. Given the importance of teamwork in achieving organisational goals, work relationships are critical. Through the achievement of goals work relationships, thus, impact on work identity directly. The extract that follows highlights the importance of working with colleagues towards the same goals and objectives:

'Relationships at work with my colleagues (immediate peers). If I want to move the department in a certain direction I have to support and buy in from them. That is my base and foundation at work and that is very important.' (Participant 18 A/B, international manufacturing organisation employee, p. 3)

The participants also highlighted the value of these relationships as a source of feedback in the process of selfimprovement:

'There's some I just have to tell what to go and do, so it has changed, but I have a very open relationship with them, and even, I insist that they give me upward feedback, so that obviously I can improve.' (Participant 3A/B, international manufacturing organisation employee, p. 15)

Relationships at work included those with managers ('bosses'), colleagues and reportees ${ }^{2}$. In rare instances poor relationships (usually attributed to bad experiences) were mentioned. However, in most cases relationships at work were viewed as a source of significant support and guidance.

Networking, in terms of relationships at work, was also highlighted as a strategy through which people develop and improve knowledge about their work by seeking input and guidance from people in similar work environments. This is beneficial for both the individual and the organisation, as illustrated in the following extract:

'Yes...but I make a lot of it myself, I get involved with a lot of people, I know all the people around the company. I know lots of people in different companies. I like to get to different companies, to see what they are doing.' (Participant 4A/B, international manufacturing organisation employee, p. 36)

\section{Theme 3: Career management}

Within the theme career management, people follow strategies in relation to the development of their professional and vocational lives. These are followed at various times throughout their working lives as they work towards goal achievement in their careers.

\section{Strategy 6: Education}

Education is an important aspect of every person's individual development, not only within their work but also in their personal lives. It provides them with a foundation to fall back on when difficulties arise in the organisation and ensures their survival in the job market. People use education to control their career paths and are aware of the fact that a good education promotes potential success, including financial success in life and at work. In one interview a person alluded to her decision to study for a degree based on the fact that she wanted to be challenged and enjoyed calculations. The degree was in her field of interest and so this factor provided an important consideration for choosing to study in this specific field:

'So I did a BCom and I majored in accounting because everybody was complaining about accounting being so difficult and because I did math at school, I enjoy numbers, so I majored in accounting.' (Participant 9A/B, international manufacturing organisation employee, p. 1)

Although reference was made to formal education, as highlighted above, it was clear that people regard this as only one form of education. Several people described using their work as an opportunity to learn, and as a means of informal education. The extract below is from a person recruited into a new position. He is not yet familiar with his new work and he considers it an opportunity to learn and expand his knowledge of the job. Naturally, it is important that he is given the freedom to learn: 'My work is new and I am still learning and getting to grips with a lot of stuff. I deal a lot with HRD and I don't talk about it as I'm still learning' (Participant 7B, international manufacturing organisation employee, p. 1).

In terms of informal education, the South Africa government has focused on the recognition of informal learning and practical experience and has attempted to formalise this form of education. This takes place through Sector Education and Training Authorities (SETAs) and their Education, Training and Quality Assurance (ETQA) systems, which are run in collaboration with the South African Qualifications Authority (SAQA). This system provides people with opportunities to develop themselves within their current work and receive recognition for the experience they have built up over the years. This allows people to become 'qualified' in their specific trade fields and take their qualifications with them when they leave the organisation. This is highlighted in the following extract:

'In fact, I was looking into the SETA setup, what qualification do I need to get, so that if I retire from here, I can join a group where you do training. And I think that the older folk need to be used in 
that area. Educate as we get older, we need to be educated to be able to be teachers for the younger generation.' (Participant IA, international manufacturing organisation employee, p. 4)

\section{Strategy 7: Career mobility}

The career Mobility strategy refers to a person's decision to either stay within a specific work environment or to find an alternative to this environment. Alternatives may be sought for the purpose of growth and development, improved benefits or need for change. In this way, the person takes control of his or her career. Some people use this strategy on a continual basis and are reluctant to stay within one job or organisation for a long period of time as they fail to see how it will benefit them. In the extract below, the person was not unhappy in her work but needed a change. As an academic, she had flourished and considered it part of her personal identity. However, she wanted to move into industry in order to develop herself in her professional field: 'I was not unhappy in academia, but I felt I needed to move into industry' (Participant 6A, international manufacturing organisation employee, p. 1).

Work goals refer to the goals people set for themselves as part of their career development and motivation for goal achievement. Work goals are considered important in career advancement and achieving vocational objectives. Through setting goals people are able to meet their need for challenge and competition. In addition, this ensures career advancement as well as recognition. In an interview, one person highlighted the importance of organisational goals, as these allow him to align his personal work goals with those of the organisation, as illustrated by the following extract: 'Working with goals and goals are there to let everyone know where we are going...' (Participant 17A/B, international manufacturing organisation employee, p. 5).

\section{Theme 4: Negotiating balance}

The importance of balancing the demands of work and personal life is considered in this theme. The strategies people use to manage the impact of their work identities are considered. This theme includes aspects for managing boundaries and work-life integration.

\section{Strategy 8: Managing boundaries}

Many employees highlighted 'managing boundaries' as a strategy of setting boundaries. Although they acknowledge that it is not always easy, people stress that making a conscious decision and setting clear boundaries develops their ability to focus on what is important in the moment, be it work, family or the self. This requires great flexibility and the ability to recognise when one needs to simply relax. These people are able to find balance and ensure their quality of life. This is significant in the organisational context where many people work well beyond the recommended working hours. In some instances this provides people with a sense of satisfaction and fulfilment as their hobbies add value to others. Given that the manufacturing organisation in question is operational 24 hours a day, 7 days a week and 365 days a year, employees must actively create and manage boundaries, as illustrated in the following extracts: 'My lines between work and home are distinct and have become more distinct as time goes on' (Participant 5B, international manufacturing organisation employee, p. 10).

Flexibility and the ability to control aspects of the environment are also crucial in accomplishing personal goals. Flexibility was best illustrated by a person who negotiated, on joining the organisation, to have three months leave every year to travel home (abroad) to visit her family. She views this as integral to the success of her family and home life. The same person was offered a position in another division of the same organisation, but turned it down because she requires a great deal of flexibility and was not sure this would be provided in the other position:

'My work fits in very well with my personal life, one of the reasons why I haven't progressed further is that I take very long leave every year, perhaps 2 or 3 months to go overseas, to spend time with my kids, so that was a decision I made, it's very difficult I think to have a career and a family for women.' (Participant 12A/B, international manufacturing organisation employee, p. 2)

In addition, employees often referred to the importance of relaxation. Relaxation includes certain personal activities, interests or hobbies they enjoyed outside of work, such as, fishing, soccer, gym, music and biking. These activities provide an outlet for their frustration and an opportunity to relax. Whilst many people engage in activities for pure relaxation, some people expressed the need for quiet time to unwind:

'Me, I want to be on my own and my wife understands that. When I have my quiet day, my wife keeps shut, stay out of the way and I have my quiet time, don't talk a lot, the kids will ask what is wrong, dad just wants to be by himself, then I start listening to some Reggae just relax - I don't sometimes just on my own. I get in the car, drive out in the field park under the tree and just relax.' (Participant 2A/B, international manufacturing organisation employee, p. 7)

\section{Strategy 9: Work-life integration}

The strategy of 'managing boundaries' described above addresses the needs of people for work-life balance, thus, ensuring clear boundaries between the two. However, two people displayed the strategy of associating their work with other aspects of life. The first person portrayed a seamless join between the two contexts and it has become natural for him to integrate what he learns and derives from work into his home life, thus enhancing the resultant benefit. This is illustrated as follows:

'Most of principles learned, can apply at home and everywhere; then you become a better person and you grow a lot. You have to be considerate as well, inform people about the change in strategy; then you will achieve your goals. You can apply these principles everywhere and become a better person.' (Participant 17A/B, international manufacturing organisation employee, p. 3) 
The second participant explained how the effects of relaxation, in this instance reflecting a cultural interest, influenced the work environment. This is illustrated in the following extract: 'I actually play Indian music, for me, it's a point of relaxation, a point of calm, I obviously carry that in my workplace' (Participant 10A/B, international manufacturing organisation employee, p. 4).

\section{Discussion}

The main objective of this article was to use people's narratives to explore the strategies they follow in identity work as they regulate and negotiate their identities at work, taking into consideration the multiple contexts informing and influencing these identities. Identity work has not been studied previously, in the South African context, and the novelty of this study is, thus, in the context provided by the South African employment landscape. We found that individuals follow several strategies both inside and outside the work context as they engage in the process of regulating and negotiating their work identities.

Although the theme of personal philosophies strategies may appear somewhat abstract, participants in this study followed these strategies in a practical way to create meaning in difficult situations, set standards for acceptable behaviour (in life and work), and as a source of strength in times of difficulty. Similar strategies present in the literature include ethical aspects, namely loyalty and trust (Gini, 1998), hardiness and resilience (Lee \& Mitchell, 1994), and confidence (Kirpal, 2004), all of which are relevant to both one's work and personal life. Kreiner et al. (2006) also discuss tapping spiritual resources as a dual function strategy, and this is an expected finding as their sample consisted of Episcopalian priests. However, it was also evident in our own sample, that of a diverse group of people in a secular organisation. The various strategies, included under personal philosophies, can be likened to the foundations on which work identity is built as well as a base line against which various external demands are measured, thus, these provide set boundaries regarding what is considered acceptable and unacceptable. Work identity is a process of negotiation and the personal philosophies strategies appear to provide the foundation for all other strategies as they provide guidelines that act as a set of criteria for making decisions, planning the future and guiding behaviour. This category includes the strategy of the creation of meaning, which involves employees' actively engaging with demands in order to create sense and coherence, thus, reinforcing the idea of negotiation as part of identity work.

Relationships emerged as an important theme in relation to how people define themselves and the importance of maintaining relationships through relationship work was emphasised. Kreiner et al. (2006) identified involving people as a strategy in identity work. Within their study this was seen as a means of maintaining personal identity in the face of occupational demands. In our study a far broader dependence on relationships, both inside and outside of work, emerged. Work relationships are viewed as a means of achieving goals, but even in this context they are a source of emotional support. In addition, networking (Sveningsson \& Alvesson, 2003) is also a means of achieving organisational goals. Kreiner et al. (2006) viewed relationships in the context of the role expectations of a priest, who is seen as a link with God and thus able to give support, rather than as a person who may sometimes need support. In terms of relationships outside of work, both groups found strength and fulfilment in the relationships with family and friends. Although the differing occupational demands account for some of the differences between the two samples, we believe that the dependence on relationships may be indicative of the collectivistic nature of South Africa, where considerable emphasis is placed on relationships in the context of selfdefinition.

The strategies that form part of the career management theme were very similar to those identified in the literature, such as education (Alvesson, 2001; Brown, 2004; Loogma, Umarik \& Vilu, 2004; Philipson, 2001) and mobility (Kirpal, 2004; Philipson, 2001). However, a strategy unique to the South African context was the emphasis on obtaining formal educational recognition for skills and knowledge gained on the job. This is of significant value to people who have been deprived of the opportunity to gain a formal education and have no means of achieving formal recognition for the skills they have developed. This also facilitates the use of related strategies such as mobility, as an employee with a formal qualification is able to move between different organisations and industries. In addition, the importance of work goals promotes the alignment of personal goals with organisational goals. This benefits the employee as it promotes the possibility of movement inside and outside the organisation, as employees achieve career goals.

Kreiner et al. (2006) define balance as a state people obtain by negotiating two aspects of their identity, namely work and self. In our findings, balance is regarded as a strategy rather than the achievement of a state and is included in the theme of negotiating balance. This theme includes strategies that ensure that interests outside of the work arena are protected. The strategy we termed managing boundaries is similar to Kreiner et al.'s (2006, p 1044) strategy of 'flipping the onoff switch' and refers to separating work and personal life. Kreiner et al.'s (2006) strategy of 'enacting ephemeral roles' (p. 1044) is similar to our strategy of relaxation, in that both focus on outside interests and other roles (e.g. community work) as a means of achieving balance. The strategy of flexibility, which entails negotiating career demands and adjusting these to personal goals and circumstances, was an interesting finding in this study, as it confirmed the need for people to separate themselves from their formal work contexts. The final strategy of work-life integration is similar to 'merging one's role with (work) identity' (Kreiner et al., 2006, p. 1044), which is a strategy that allows for integrating work and personal identity.

The process of negotiating work identity relies strongly on the relationships between the themes identified. In the social context, where people negotiate their work identities, personal identity acts as a foundation for this process through individual agency (Gini, 1998). This agency is integral to 
negotiating various aspects of identity at work as well as in other social environments (Ashmore et al., 2004; Verkuyten, 2005). The strategies thus operate across all spheres of an individual's life. Some of the strategies identified in this study rely on factors present in the environment outside of work, namely education (formal), relationships with family, and living according to a personal ethic. Some of the other strategies, including relationships at work and one's living work ethic, are followed primarily in the work environment. In addition, the relationship work strategy is followed in multiple contexts and the flexibility and managing boundaries strategies are followed to manage tensions between the demands of various contexts (Kreiner et al., 2006).

Methodologically, the narrative approach undertaken (Beech, 2008; Kornberger \& Brown, 2007; Watson, 2008) allowed us to identify strategies unique to the context in which our participant employees worked. In a similar manner to Kreiner et al.'s (2006) study of Episcopalian Priests, this study provides a conceptual basis for identity work and the strategies available to people in regulating their work identity. However, this study takes into consideration the unique South African working context as a background (Eaton \& Louw, 2000; Jackson, 1998; Van de Vijver \& Rothman, 2004). Although the employees in this sample made use of similar strategies to their global counterparts, some unique aspects did emerge. In particular, the opportunities offered by that South African Quality Assurance Act (Government Gazette no. 1521, 1995), which allows for the formal recognition of skills and knowledge gained in the work environment, influenced the way in which the education strategy was applied.

The creation of meaning as a personal philosophy should also be understood against the background of legislation such as The Employment Equity (EE) Act (Government Gazette, no. 19370. 1998) and the Broad Based Black Economic Empowerment (BBBEE) Act (Government Gazette no 25899, 2003), which promote the interests of Historically Disadvantaged Individuals (HDIs), through the promotion of Black management and ownership, sustainable development, and preferential procurement. These acts have implications for non-designated groups (particularly White males) whose career opportunities and growth are sometimes negatively impacted. This means that significant identity work is necessary for these individuals and one of the strategies employed is that of the creation of meaning. Through this strategy employees attempt to make sense of the challenges facing them.

\section{Recommendations}

Understanding work identity and the processes through which it is created and negotiated is important for organisations (Beech, 2006; Svenningson \& Alvesson, 2003). This is because 'who I am' contributes towards the organisational 'who we are' and ultimately to 'what we would like to achieve' (Ashmore et al., 2004). Understanding work identity has implications for organisations as they strive to achieve their goals. In this regard, several aspects from this study are important.
Firstly, the relative importance of family and work relationships in negotiating work identity needs to be understood, acknowledged, and supported through organisational practices. Secondly, the powerful effect of employees' personal philosophies in regulating work identity must be understood and given space for expression and valuation. Thirdly, it is important that people understand the effect of their actions and goals on their personal identity at work, and how these relate to organisational goal achievement. Creating an understanding of how people negotiate personal identity, and their control over 'who they are', empowers them to make decisions which could be beneficial to them and the organisation. Fourthly, employees (whether or not currently employed or seeking work) need to be aware of the possible strategies available to them in the identity work process. Finally, the inter-relatedness of strategies highlights the importance of people as holistic beings who draw on different aspects of their lives and go to great lengths in order to define themselves.

\section{Limitations}

Several limitations of this study need to be mentioned. Firstly, both rounds of interviews were conducted in a two week radius which is a short period of time for planning and preparation between interviews. This was aided however with a debriefing session after the first round of interviews to assist with the preparation for the second round of interviews. It aided by allowing the project team, rather than the individual fieldworker, to reflect on the first round of interviews and prepare for the second round of interviews. Secondly, as a result of time constraints, of the interviews being conducted by several fieldworkers, with different research needs, only 19 were fully transcribed and therefore included in this study from the original 28 interviews conducted. Thirdly, as a consequence of the qualitative approach and small sample size in this study, the findings were limited to the small sample in this study. It is, therefore, important that further inquiry is made, of both a qualitative and quantitative nature, across various contexts that would result in general models developing about the identity work strategies that aid in the negotiation and regulation of employee work identity.

\section{Conclusion}

The exploration of strategies in work identity yielded promising initial findings, however, the results cannot be generalised to the general population. Similar studies would be useful in organisations in other developing contexts, where diversity, culture, the role of government, and legislation have an impact on employment.

It is recommended that further exploration of individual work identity, the identity work process, strategies for negotiating and regulating identity, and characteristics that are prevalent in the South African context. Further research should consider the relationship between professional identity and work identity, and the real links which exist between these forms of identity, work engagement and employee productivity. 


\section{Acknowledgements}

The research reported in this article is the product of a collaborative research project between the University of Johannesburg and the Vrije University, Amsterdam. This report was conducted with the assistance of financial support from SANPAD. The conclusions drawn or opinions expressed in this article are those of the authors and do not necessarily reflect the views of SANPAD.

\section{Competing interest}

The authors declare that they have no financial or personal relationship(s) which may have inappropriately influenced them in writing this paper.

\section{Authors' contributions}

B.G.A. (University of Johannesburg) was responsible for the date analysis of the study as well as for the preparation of the manuscript. A.C. (University of Johannesburg) acted as the study leader.

\section{References}

Adams, B.G., Van de Vijver, F.J.R., \& De Bruin, G.P. (in press). Identity in South Africa: Examining self-descriptions across ethnic groups. International Journal of Intercultural Relations.

Adler, P.A., \& Adler P. (1994). Observational techniques. In N.K. Denzin \& Y.S. Lincoln (Eds.), Handbook of qualitative research, (pp. 377-390). Thousand Oaks, CA: Sage Publications.

Ainsworth, S. (2001). The discursive construction of older worker identity: A reflection on the processes and methods. Tamara: Journal of critical postmodern organisation science, 1(4), 29-46.

Alvesson, M. (2001). Knowledge work: Ambiguity, image and identity. Human Relations, 54, 863-886. http://dx.doi.org/10.1177/0018726701547004

Alvesson, M., \& Willmott, H. (2002). Identity Regulation as Organizational Control, Journal of Management Studies, 39, 619-44. http://dx.doi.org/10.1111/1467 6486.00305

Ashmore, R.D., Deaux, K., \& McLaughlin-Volpe, T. (2004). An organizing framework $f$ or collective identity: Articulation and significance of multidimensionality. Psychological Bulletin, 130, 80-114. http://dx.doi.org/10.1037/0033-2909.130.1.80 PMid:14717651

Bailey, C.A. (2007). A guide to qualitative research. Thousand Oaks, CA: Pine Forge Press.

Beech, N. (2008). On nature of dialogic identity work. Organization, 15(1), 51-74. http://dx.doi.org/10.1177/1350508407084485

Breakwell, G.M. (1986). Coping with threatened identities. London, UK: Methuen.

Broad Based Black Economic Empowerment Act No. 53. (2003). Government Gazette. (No. 25899), Pretoria, South Africa: Government Printers.

Brown, A. (2004). Engineering identities. Career development international, 9(3), 245-273. http://dx.doi.org/10.1108/13620430410535841

Buche, M.W. (2006). Influence of gender on IT professional work identity: Outcomes from a PLS study. Proceedings of the 2008 ACM SIGMIS CPR conference on computer personnel doctoral consortium and research, 03-05 April 2008, Charlottesville, VA, USA: ACM SIGMIS CPR.

Charmaz, K. (1995). Grounded theory. In J.A. Smith, R. Harre \& L. Van Langenhoven (Eds.), Rethinking methods in psychology, (pp. 27-49). London, UK: Sage Publications.

Charmaz, K. (2010). Constructing grounded theory: A practical guide through qualitative analysis. London, UK: Sage Publications.

De Braine, R., \& Roodt, G. (2011). The Job Demands-Resources model as predictor of work identity and work engagement: A comparative analysis. SA Journal of Industrial Psychology/SA Tydskrif vir Bedryfsielkunde, 37(2), 11 pages. http:// Industrial Psychology/SA Tydskrif vir
dx.doi.org/10.4102/sajip.v37i2.889

Denzin, N.K. (1998). The new ethnography. Journal of Contemporary Ethnography, 27, 405-415. http://dx.doi.org/10.1177/089124198027003006

Eaton, L., \& Louw, J. (2000). Culture and self in South Africa: Individualism-collectivism predictions. Journal of Social Psychology, 140, 210-217. http://dx.doi. org/10.1080/00224540009600461, PMid:10808644

Employment Equity Act no. 55. (1998). Government Gazette. (No. 19370), Pretoria, South Africa: Government Printers.

Esterberg, K.G. (2002). Qualitative Methods in Social Research. Boston, MA: McGraw Hill.
Giddens, A. (1990). The consequences if modernity. Oxford, UK: Polity.

Gini, A. (1998). Work, identity and self: How we are formed by the work we do. Journal of Business Ethics, 17, 707-714. http://dx.doi.org/10.1023/A:1017967009252

Goulding, C. (2007). Grounded theory: A practical guide for management, business and market researchers. Thousand Oaks, CA: Sage Publications Ltd.

Guba, E.G., \& Lincoln, Y.S. (1994). Competing paradigms in qualitative research. In N.K. Denzin \& Y.S. Lincoln (Eds.), Handbook of qualitative research, (pp.105-117). Thousand Oaks, CA: Sage Publications Ltd.

Hogg, M.A., Terry, D.J., \& White, K.M. (1995). A tale of two theories: A critical comparison of identity theory with social identity theory. Social Psychology Quarterly, 58, 255-269. http://dx.doi.org/10.2307/2787127

Jackson, T. (1998). Managing change in South Africa: Developing people and organisations. The International Journal of Human Resource Management, 10, 306-326. http://dx.doi.org/10.1080/095851999340576

ledema, R., \& Scheeres, H. (2003). From doing work to talking work. Renegotiating knowing, doing and identity. Applied Linguistics, 24, 316-37. http://dx.doi. org/10.1093/applin/24.3.316

Kirpal, S. (2004). Researching work identities in a European context. Career Development International, 9(3), 199-221. http://dx.doi.org/10.1108/13620430410535823

Kornberger, M., \& Brown, A.D. (2007). 'Ethics' as a discursive resource for identity work. Human Relations, 60, 497-518. http://dx.doi.org/10.1177/0018726707076692

Kreiner, G.E., Hollensbe, E.C., \& Sheep, M.L. (2006). Where is the ' $m e^{\prime}$ among the 'we'? Identity work and the search for optimal balance. Academy of Management Journal, 49(5), 1031-1057. http://dx.doi.org/10.5465/AMJ.2006.22798186

Lee, T.Q., \& Mitchell, T.R. (1994). An alternative approach: The unfolding model of voluntary employee turnover. The Academy of Management Review, 19(1), 5189.

Leidner, R. (1991). Serving hamburgers and selling insurance: Gender, work, and identity in interactive service jobs. Gender \& Society, 5, 154-177. http://dx.doi. identity in interactive service jobs. Gen
org/10.1177/089124391005002002

Loogma, K., Umarik, M., \& Vilu, R. (2004). Identification - flexibility dilemma of IT specialists. Career development international, 9(3), 323-348. http://dx.doi. org/10.1108/13620430410535878

Mason, J. (2002). Qualitative research. London, UK: Sage Publications.

McAdams, D.P. (1993). The stories we live by: Personal myths and the making of the self. New York, NY: William Morrow and Company.

McMillan, J.H., \& Shumacher, S. (2001). Research in education. A conceptual introduction. (5th edn.). New York: Longman.

Neuman, W.L. (2000). Social Research Methods: Qualitative and Quantitative Approaches. Needham Heights, MA: Allyn \& Bacon.

O'Conner, K.E. (2007). 'You choose to care'. Teachers, emotions and professional identity. Teaching and Teacher Education, 24, 117-126. http://dx.doi. org/10.1016/j.tate.2006.11.008

Parker, I. (2005) Qualitative Psychology: Introducing Radical Research. Buckingham, UK: Open University Press

Philipson, I. (2001). Work is life, a psychologist looks at identity and work in America. Retrieved May 07, 2008, from www.psychotherapy.net

Reetley, A. (2003). A literature review on grounded theory. Unpublished master's dissertation, University of Johannesburg, Johannesburg, South Africa.

Rothbard, N.P., \& Edwards, J.R. (2003). Investment in work and family roles: A test of identity and utilitarian motives. Personnel Psychology, 56, 699-730. http://dx.doi. org/10.1111/j.1744-6570.2003.tb00755.x

Rounds, J. (2006) Doing identity work in museums. Curator: The Museum Journal, 49 133-150. http://dx.doi.org/10.1111/j.2151-6952.2006.tb00208.x

Rubin, H.J., \& Rubin, I.S. (1995). Qualitative Interviewing: The art of hearing dada Thousand Oaks, CA: Sage Publications.

Shih, M., \& Sanchez, D.T. (2005). Perspectives and research on positive and negative implications of having multiple racial identities. Psychological bulletin, 131(4), 569-591. http://dx.doi.org/10.1037/0033-2909.131.4.569 PMid:16060803

Sluss, D.M., \& Ashforth, B.E. (2007). Relational identity and identification: Defining ourselves through work relationships. Academy of Management Review, 31(1), 9-32. http://dx.doi.org/10.5465/AMR.2007.23463672

South African Quality Assurance Act no. 55. (1995). Government Gazette. (No. 1521), Pretoria, South Africa: Government Printers.

Sparkes, A.C. (2002). Telling tales in sport and physical activity: A qualitative journey Leeds, UK: Human Kinetics.

Sveningsson, S., \& Alvesson, M. (2003). Managing managerial identities: Organisational fragmentation, discourse and identity struggle. Human Relations, 56(10), 11631193. http://dx.doi.org/10.1177/00187267035610001

Swann, W.J., Johnson, R.E., \& Bosson, J.K. (2009) Identity negotiation at work Research in Organizational Behavior, 29, 81-109. http://dx.doi.org/10.1016/j. riob.2009.06.005

Van de Vijver, A.J.R., \& Rothmann, S. (2004) Assessment in multicultural groups: The South African case. South African Journal of Industrial Psychology, 30(4), 1-7.

Verkuyten, M. (2005). The social psychology of ethnic identity. New York, NY Psychology Press. http://dx.doi.org/10.4324/9780203338704

Walsh, D. (1998). Doing ethnography. In C. Seale (Ed.), Researching society and culture. London, UK: Sage Publications.

Watson, T.J. (2008). Managing Identity: Identity work, personal predicaments and structural circumstances. Organization, 15(1), 121-143. http://dx.doi. org/10.1177/1350508407084488 